\title{
Clinical case discussion: using a reflecting team
}

\author{
John Launer
}

Doctors discuss clinical cases every day. The routine way of doing this, whether in ward rounds, team meetings or other conversations, is so familiar that few give it any thought. Generally speaking, one person presents a case, and then everyone else chips in with questions, information and advice until some kind of decision is reached-perhaps an investigation, diagnosis or treatment. This all seems very simple and straightforward. Yet if you study case discussions closely, they appear more problematical. For a start, they often remain narrowly focussed on the technical facts of the case, and may ignore the patient's daily function, life history, family circumstances, beliefs or wishes. When the patient's lifestyle does come into view, it may become the subject of moral judgements rather than sympathetic consideration. This is common experience, but has been attested for a long time in sociological research as well. ${ }^{1-3}$ There are other problems in case discussions too. Some people's voices can dominate more than others: typically, men speak more than the women, and seniors more than juniors. Staff members who are dogmatic, or more certain of their positions, may claim more air time than those who are diffident. Sometimes doctors are more vocal than others, although in some multidisciplinary case discussions, other professions including social workers may speak more forcefully. Presenters can feel bombarded by too much advice, and become confused or stop listening as a result. Quite often, the case presenter's story is interrupted by other people telling anecdotes about similar cases-or about entirely different ones that seem irrelevant to the case in question. In reality, the invisible rules that govern standard case discussions are somewhat random, and they may not meet the needs of either the patient or the clinician nearly as effectively as they might.

There are a number of methods for case discussion specifically designed to overcome these limitations. Such methods include "Balint groups", named after the

Correspondence to Dr John Launer, Faculty Development, Health Education North West London, Stewart House, 32 Russell Square, London WC1B 5DN, UK; john.launer@londondeanery.nhs.uk doctor who devised them over fifty years ago, and aimed at encouraging general practitioners to focus in a disciplined way on the emotional dimensions of their work, including the doctor-patient relationship. ${ }^{45}$ More recently, hospitals in the United States and elsewhere have introduced Schwartz rounds, which allow multiprofessional staff groups to discuss the psychosocial challenges of their case load. ${ }^{6}$ Collaborative learning groups of this kind are usually based on a fixed set of rules allowing extended, in-depth discussion of a single case. This can have tremendous benefits, including learning important general points from close examination of particular incidents. ${ }^{7}$ At the same time, all these kinds of approaches require highly trained facilitators, and a great deal of time for each single case. In addition, they usually exclude "clinical" talk, focussing on the clinicians' feelings instead. This can be frustrating if technical or administrative decisions need to be made as well. None of them are really suitable for everyday case discussions, where affective learning has to be combined with the management of clinical care in a relatively short period of time.

\section{STRUCTURE AND FOCUS}

There is one simple approach that can bring structure and focus to any clinical case discussion, and allows a group of clinicians to address both the biomedical and psychosocial aspects of patient care. Few clinicians or educators seem to know about it, and yet just about anyone can apply it, whether they have had training in the method, or have only observed it once or twice and grasped some simple rules. It combines the features of routine team conversations and collaborative learning groups, and can be used for conversations lasting anything from a few minutes to an hour. The method is known as "a reflecting team".

Reflecting teams originated in the world of mental health care, ${ }^{8}$ but have been successfully adapted in order to train doctors and health professionals in the skills needed for supervision and effective case discussions. ${ }^{9}$ The method is based on a very simple set of conversational rules (see box 1).

At first, using a reflecting team can seem a little artificial or inflexible. Yet case presenters nearly always report afterwards what a relief it is to speak without interruption, to have an opportunity to clarify the case, and to listen to a range of different perspectives, without having to give an immediate response. Team members find they can use questions to raise a whole range of different aspects of the problem, including the technical details as well as the psychological dimensions of the case or its impact on the presenter. If they wish, they can also discuss the wider organisational or resource issues affecting the case. Letting presenters listen to everyone else in silence gives them time to digest any ideas properly, and to take ownership of whatever decision they make as a result. It is relatively easy for someone to facilitate the whole conversation, make sure that everyone follows the rules, and invite each person present to ask at least one question and expresses a view. The rules are adaptable according to circumstances: for example, in a training context, juniors can be invited ask questions and offer their opinion before their

\section{Box 1 Conversational rules for case discussion, using a reflecting team}

1. The case presenter first talks without interruption for a couple of minutes (or longer if time permits).

2. Other members of the team then ask questions to clarify the case or its context, but they cannot give advice or make any suggestions (even indirect ones like "have you thought of...?").

3. The case presenter then poses a question or task for the team to consider (for example "is there any aspect of this case I might be missing?" or "what would you do in this situation?").

4. The team responds by discussing this, but without looking at the presenter, or involving him or her in the conversation.

5. Finally, the presenter gives feedback to the team about what was most helpful in the discussion, and what action it will lead to. 
seniors do. The method can also be used for discussing non-clinical issues, including difficulties in the workplace.

As well as producing benefits in individual cases, regular use of the approach can instil a more reflective and collaborative approach to medicine. Participants in reflecting teams soon discover there is rarely a single way of looking at any clinical case, nor any single correct way of managing it. They can become more at ease with clinical uncertainty, more respectful of their colleagues' opinions, more comfortable about having their own ideas subordinated to the combined expertise of the team, and more compassionate towards complex or challenging patients. ${ }^{10}$ There are few more salutary experiences in medicine than discovering that the collective mind of a reflecting team is more powerful than your own mind can ever be on its own.

Twitter Follow John Launer at @JohnLauner

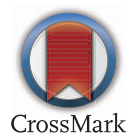

To cite Launer J. Postgrad Med J 2016;92:245-246.

Postgrad Med J 2016;92:245-246.

doi:10.1136/postgradmedj-2016-134079

\section{REFERENCES}

1 Anspach RR. Notes on the sociology of medical discourse: the language of case presentation. J Health Soc Behavior 1988;29:357-75.

2 Atkinson P. Medical Talk and Medical Work: The Liturgy of the Clinic. London: Sage, 1995.
3 Donnelly J. The language of medical case histories. Ann Int Med 1997;127:1045-48.

4 Balint M. The Doctor, His Patient and the Illness. London, Pitman, 1957.

5 Balint E, Courtenay M, et al. The Doctor, the Patient and the Group. Balint Revisited. London: Routledge, 1993.

6 Point of Care Foundation. Schwartz Rounds. http:/l www.pointofcarefoundation.org.uk/Schwartz-Rounds/ (accessed 28 Feb 2016).

7 Launer J. Collaborative learning groups. Postgrad Med J 2015;91:473-4.

8 Andersen T. The reflecting team: dialogue and metadialogue in clinical work. Fam Proc 1987;26: 415-428.

9 Launer J. Training in narrative-based supervision: conversations inviting change. In: Sommers $L S$, Launer J, eds., Clinical Uncertainty in Primary Care: The Challenge of Collaborative Engagement. New York, NY: Springer, 2013:163-176.

10 Kjaer NK, Stolberg B, et al. Collaborative engagement with colleagues may provide better care for 'heart-sink' patients. Ed Primary Care 2015;26:233-9. 